\title{
Reversible Water-Induced Phase Changes of Cobalt
}

\section{Oxide Nanoparticles}

Dennis Hein ${ }^{a, b}$, Garlef Wartner ${ }^{a, b}$, Arno Bergmann ${ }^{c}$, Miguel Bernal ${ }^{c, d, \dagger}$, Beatriz Roldan Cuenya ${ }^{c}$, and Robert Seidel ${ }^{a, b, *}$

${ }^{a}$ Helmholtz-Zentrum Berlin für Materialien und Energie (HZB), Albert-Einstein-Straße 15, 12489 Berlin, Germany

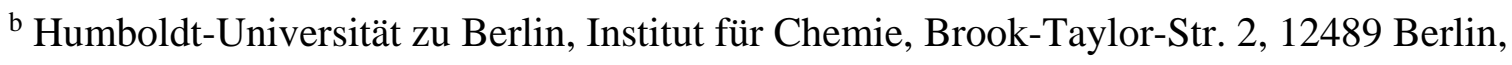
Germany

c Fritz-Haber-Institut der Max-Planck-Gesellschaft, Faradayweg 4-6, 14195, Berlin, Germany

d Department of Physics, Ruhr-University Bochum, 44780 Bochum, Germany

* corresponding author

$\dagger$ Present Address

Faculté des Sciences, Chemistry of Surfaces, Interfaces and Nanomaterials (ChemSIN), Université Libre de Bruxelles, Avenue Franklin Roosevelt 50, 1050 Bruxelles, Belgium.

ABSTRACT. Cobalt oxides have been identified as highly active catalysts for the electrochemical water splitting and oxygen evolution reaction. Using near-ambient pressure resonant photoelectron 
spectroscopy, we studied changes in the metal-oxygen coordination of size-selected core-shell $\mathrm{CoO}_{\mathrm{x}}$ nanoparticles induced by liquid water. In dry conditions, the nanoparticles exhibit an octahedrally coordinated $\mathrm{Co}^{2+}$ core and a tetrahedrally coordinated $\mathrm{Co}^{2+}$ shell. In the presence of liquid water, we observe a reversible phase change of the nanoparticle shell into octahedrally coordinated $\mathrm{Co}^{2+}$ as well as partially oxidized octahedrally coordinated $\mathrm{Co}^{3+}$. This is in contrast to previous findings, suggesting an irreversible phase change of tetrahedrally coordinated $\mathrm{Co}^{2+}$ after the oxygen evolution reaction conditioning. Our results demonstrate the appearance of waterinduced structural changes different from voltage-induced changes and help us to understand the atomic scale interaction of $\mathrm{CoO}_{\mathrm{x}}$ nanoparticles with water in electrochemical processes.

KEYWORDS. near-ambient pressure XPS, solid-liquid interface, cobalt oxide, reversible phase change, core-shell nanoparticles 
The electrochemical water splitting process consists of two half reactions, namely the hydrogen evolution reaction (HER) and oxygen evolution reaction (OER) for which commonly expensive and rare noble elements like Pt and Ir/Ru based catalysts are used, respectively, hindering the commercial application. ${ }^{1,2}$ For this reason, extensive research efforts are made to find abundant, active and stable electrocatalysts, with $3 \mathrm{~d}$ transition metal oxides being a promising material class. ${ }^{1,2}$ Key catalytic performance parameters such as the efficiency and stability, depend on molecular processes determined by the electronic-structure at the solid-liquid interface between the electrocatalyst and the electrolyte. An in-depth insight into such an interface and its evolution under different chemical environments and under potential control can be now achieved thanks to modern spectroscopic tools such as near-ambient pressure photoelectron spectroscopy (NAP-XPS).

Due to its abundance and catalytical activity we focus on cobalt oxide nanoparticles (NPs). ${ }^{1,3-11}$ The investigation of different cobalt oxide NPs revealed that they have similar catalytic activities for the oxygen evolution reaction (OER) independent of their oxidation state and coordination, with $\mathrm{Co}_{3} \mathrm{O}_{4}$ being the most stable against corrosion. ${ }^{1}$ However, it has been shown that the nearsurface oxygen chemistry of $\mathrm{CoOx}(\mathrm{OH}) \mathrm{y}$ and redox electrochemistry are correlated to the catalytic activity, showing the importance of reducible $\mu_{2}-\mathrm{OH}$ bridged $\mathrm{Co}^{3+}$ sites. ${ }^{12}$

Bulk cobalt oxide is thermodynamically stable at room temperature in two forms: 1) rocksalt CoO, which consists of octahedrally $\left(\mathrm{O}_{\mathrm{h}}\right)$ coordinated $\mathrm{Co}^{2+}$, and 2) spinel $\mathrm{Co}_{3} \mathrm{O}_{4}$, consisting of the tetrahedral $\left(\mathrm{T}_{\mathrm{d}}\right)$ coordinated $\mathrm{Co}^{2+} \mathrm{A}$ site and the $\mathrm{Oh} \mathrm{Co}^{3+} \mathrm{B}$ site. ${ }^{13-15}$ Selectively replacing a phase of spinel $\mathrm{Co}_{3} \mathrm{O}_{4}$ with inactive $\mathrm{Zn}^{2+}$ or $\mathrm{Al}^{3+}$ revealed that under OER conditions $\mathrm{O}_{\mathrm{h}} \mathrm{Co}^{3+}$ forms a stable bond with -OH groups, limiting its catalytical activity, whereas $\mathrm{Co}^{2+}$ forms $\mathrm{CoOOH}^{16,17}$, as predicted by theory ${ }^{18}$. This transformation of $\mathrm{T}_{d} \mathrm{Co}^{2+}$ towards $\mathrm{CoOOH}$ in spinel $\mathrm{Co}_{3} \mathrm{O}_{4}$ under applied oxidizing bias is a reversible process, induced by its oxygen affinity, which is a result of 
the ability to release electrons under applied potential. ${ }^{16,17,19,20}$ Near-ambient pressure XPS of $\mathrm{Co}_{3} \mathrm{O}_{4}$ demonstrated this transformation during OER and its immutability without applied oxidizing bias. ${ }^{21}$ In contrast, $\mathrm{O}_{\mathrm{h}} \mathrm{Co}^{2+}$, the more active site for oxygen reduction reactions (ORR), transforms irreversibly into $\mathrm{Oh}_{\mathrm{h}} \mathrm{Co}^{3+}$ and $\mathrm{T}_{\mathrm{d}} \mathrm{Co}^{2+}$ during $\mathrm{ORR}^{22}$ Another irreversible transformation occurs for $\mathrm{T}_{\mathrm{d}}$ and $\mathrm{O}_{\mathrm{h}} \mathrm{Co}^{2+}$ oxides, forming $\mathrm{CoO}_{\mathrm{x}}(\mathrm{OH})_{\mathrm{y}}$ during $\mathrm{OER}$ conditioning, contrary to the mentioned reversible transformation of $\mathrm{Co}_{3} \mathrm{O}_{4}{ }^{12}$ These transformations demonstrate the significance of understanding the specific solid-liquid interface that determines the surface structure and surface processes relevant for water splitting applications.

In the case of $\mathrm{CoO}_{\mathrm{x}} \mathrm{NPs}$, Papaefthimiou et al. suggested that the core consisted of rocksalt $\mathrm{CoO}$ $\left(\mathrm{Oh} \mathrm{Co}^{2+}\right)$ surrounded by a partly wurtzite $\mathrm{CoO}\left(\mathrm{T}_{\mathrm{d}} \mathrm{Co}^{2+}\right)$ shell. ${ }^{15}$ Macroscopic wurtzite is not stable under ambient conditions, since the rocksalt structure is energetically favoured (by $0.27 \mathrm{eV}$ per $\mathrm{CoO}$, according to lattice energy calculations ${ }^{23}$ ). However, it can still occur embedded in another crystal $^{24}$ supporting its structure, or due to surface stress as a metastable phase on the nanoscale length, either as a nanoparticle ${ }^{12,14,25,26}$ or as a thin film on top of epitaxially grown rocksalt CoO. ${ }^{27,28}$ Lukashuk et al. demonstrated that the grain size of cobalt oxide influences the flexible adjustment to various reaction environments. ${ }^{29}$ Additionally, Fischer-Tropsch synthesis studies with $\mathrm{CoO}_{\mathrm{x}}$ NPs under reducing and oxidizing atmospheres showed their stability up to a temperature where bulk $\mathrm{CoO}_{\mathrm{x}}$ is easily oxidized or reduced in the respective atmospheres, e.g. 630 $\mathrm{K}$ in $\mathrm{O}_{2}$ atmosphere ${ }^{30}$, possibly due to the stabilizing wurtzite shell. ${ }^{30,31}$

Figure 1 (a) sketches the crystal structure and a simplified 3d orbital occupancy of $\mathrm{Oh}_{\mathrm{h}} \mathrm{Co}^{2+}$ and $\mathrm{T}_{\mathrm{d}} \mathrm{Co}^{2+} \cdot{ }^{12-14}$ Due to a different coordination and crystal field splitting, the order and occupation of the eg and $t_{2 g}$ levels are also different. For the tetrahedrally coordinated $\mathrm{Td}_{\mathrm{d}} \mathrm{Co}^{2+}$ case, the lower lying eg level is fully occupied, whereas the $\mathrm{t}_{2 \mathrm{~g}}$ level of the $\mathrm{O}_{\mathrm{h}} \mathrm{Co}^{2+}$ species has a one-electron 
vacancy. ${ }^{13,32}$ This vacancy will lead to a pre-peak in the Co 2p X-ray absorption spectra (XAS) of $\mathrm{Oh} \mathrm{Co}^{2+}$, making it possible to distinguish between both configurations. For comparison, Figure 1 (a) also displays the spinel $\mathrm{Co}_{3} \mathrm{O}_{4}$ crystal and its electronic structure, which consists of two-thirds $\mathrm{Oh}_{\mathrm{h}} \mathrm{Co}^{3+} \cdot{ }^{12,33}$ As will be discussed in Figure 2, we focus on the partial electron yield $\mathrm{x}$-ray absorption spectra (PEY-XAS), which are the integral of the specific Auger-electron decay channel signals (see Figure 1) as a function of the photon energy. A detailed description can be found in the methods section.

(a) $\mathrm{O}_{\mathrm{h}} \mathrm{Co}^{2+}$
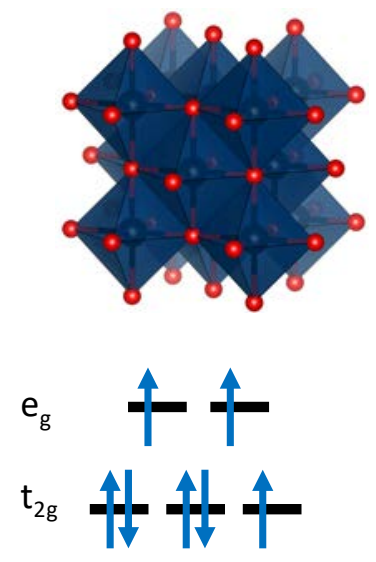

$\mathrm{T}_{\mathrm{d}} \mathrm{Co}^{2+}$
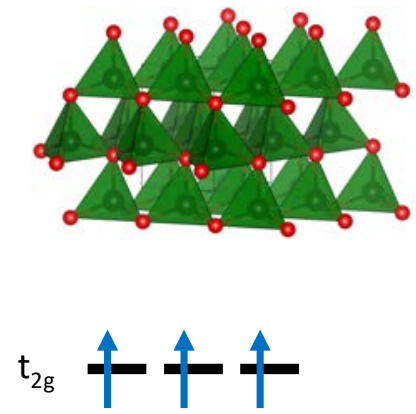

e 秥秽
$\mathrm{O}_{\mathrm{h}} \mathrm{Co}^{3+}$ $\left(+\mathrm{T}_{\mathrm{d}} \mathrm{Co}^{2+}\right)$ (b)

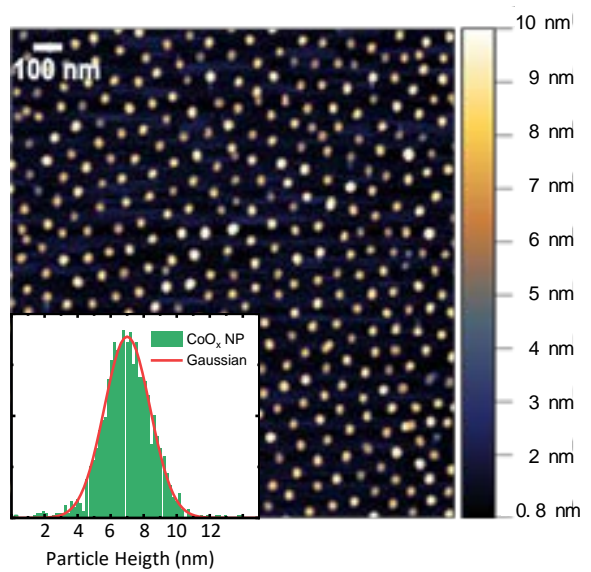

(c)

\section{XPS}

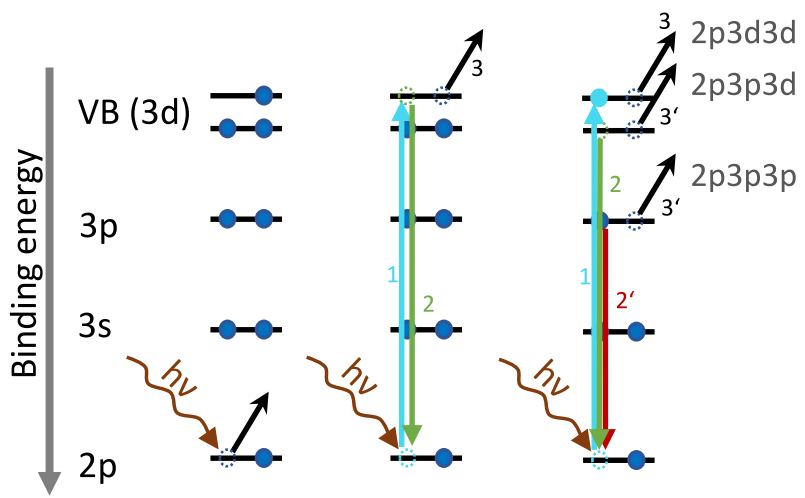


Figure 1. (a) Crystal structure of rocksalt (rs) $\mathrm{CoO}$, wurtzite (wz) $\mathrm{CoO}$, and spinel $\mathrm{Co}_{3} \mathrm{O}_{4}$. Polyhedrons represent the different coordination structures of the cobalt complexes. Dark blue octahedrons represent $\mathrm{Oh}_{\mathrm{h}} \mathrm{Co}^{2+}$, light blue octahedrons in $\mathrm{Co}_{3} \mathrm{O}_{4}$ are $\mathrm{Oh} \mathrm{Co}^{3+}$ coordinated, and green tetrahedrons are $\mathrm{T}_{\mathrm{d}} \mathrm{Co}^{2+}$. The corresponding electron occupation of the eg and $\mathrm{t}_{2 \mathrm{~g}}$ molecular orbitals for each Co-O coordination is shown at the bottom. ${ }^{13,34,35}$ (b) Atomic force microscopy image of the size-selected $\mathrm{CoO}_{\mathrm{x}} \mathrm{NPs}$ with a height of $7.0 \pm 2.0 \mathrm{~nm}$ on a $\mathrm{SiO}_{\mathrm{x}} / \mathrm{Si}(111)$ substrate. (c) Schematic representation of the (normal) XPS process, the participator and the spectator Auger decay. The latter two only occur in resonance.

This observed stability and the suggested core-shell structure of $\mathrm{CoO}_{\mathrm{x}} \mathrm{NPs}$ raises the question of the specific structural interface in contact with water. The interface properties, especially the nearsurface electronic structure, determine the molecular processes during the OER. Naturally, NAPXPS is the method of choice to experimentally investigate the electronic structure and the elementspecific surface composition. For this purpose a few-monolayer thick water film was adsorbed onto the $\mathrm{CoO}_{\mathrm{x}} \mathrm{NPs}$ solid surface in contact with a $\mathrm{SiO}_{\mathrm{x}} / \mathrm{Si}(111)$ substrate. Figure 1 (b) displays an AFM image of the used $\mathrm{CoO}_{\mathrm{x}} \mathrm{NPs}$ on a $\mathrm{SiO}_{\mathrm{x}} / \mathrm{Si}(111)$ substrate. Several groups explored already in detail the liquid film formation on several metal and metal oxide samples, e.g. $\mathrm{TiO}_{2}(110), \mathrm{Cu}(110)$, $\mathrm{Cu}(111)^{36}, \mathrm{Fe}_{3} \mathrm{O}_{4}(001)^{37}$ and $\alpha-\mathrm{Fe}_{2} \mathrm{O}_{3}(0001)^{38}$, as a function of the water vapor pressure, relative humidity and sample temperature, indicating the necessary pressure range to form a liquid $\mathrm{H}_{2} \mathrm{O}$ monolayer.

We apply soft X-ray NAP-XPS to size-selected $\mathrm{CoO}_{x}$ NPs, focusing on resonant X-ray photoelectron spectroscopy (resXPS) at the cobalt L3-edge, to gain insight into the water/CoO $\mathrm{NP}$ 
interface. Here, we report a reversible water-induced phase-change between tetrahedrally coordinated $\mathrm{Co}^{2+}$ into octahedrally coordinated $\mathrm{Co}^{2+}$ and partially oxidized octahedrally coordinated $\mathrm{Co}^{3+}$, occurring without an applied oxidizing bias. Additionally, we discuss the resonant enhanced valence-band structure of the catalyst in contact w/ and w/o liquid $\mathrm{H}_{2} \mathrm{O}$.

\section{RESULTS AND DISCUSSION}

\section{PEY-XAS under high vacuum and near-ambient pressure conditions (Co $\mathrm{L}_{3}$-edge).}

Information on the oxidation state and atomic coordination of the $\mathrm{CoO}_{\mathrm{x}} \mathrm{NPs}$ can be achieved by sweeping the photon energy through the Co L3-edge and integrating the resonant Auger decay channels to generate the 2p3p3p and 2p3p3d PEY-XAS, presented in Figure 2 (a) and (b), respectively. The notation, e.g., 2p3p3d describes a $2 p$ hole that is refilled by a 3p electron and the excess energy is transferred to a 3d electron that leaves the system. In all measured PEY-XA spectra we subtracted a linear background and normalized to the absorption maximum at around $\mathrm{E}_{\mathrm{ph}}=$ 778.1eV. Both black PEY-XA spectra were measured under high vacuum conditions at $2.5 \times 10^{-5}$ mbar. For comparison, in Figure 2 (c) we present calculated spectra by Bergmann et al. ${ }^{12}$ for $\mathrm{T}_{\mathrm{d}}$ $\mathrm{Co}^{2+}, \mathrm{Oh}_{\mathrm{ho}}{ }^{2+}$ and $\mathrm{O}_{\mathrm{h}} \mathrm{Co}^{3+}$ species, conducted using atomic positions calculated by density functional theory, which were employed into $a b$ initio crystal field multiplet calculations ${ }^{39}$. The absorption spectra of the $\mathrm{CoO}_{\mathrm{x}}$ NPs under high vacuum conditions are a superposition of spectra from $\mathrm{T}_{\mathrm{d}} \mathrm{Co}^{2+}$ and $\mathrm{O}_{\mathrm{h}} \mathrm{Co}^{2+}$ phases, as seen in comparison with the calculated spectra. One spectral fingerprint for $\mathrm{Oh} \mathrm{Co}^{2+}$ is the extra intensity at 777.2 eV (marked with $\mathbf{A}$ in Figure 2), which reflects the different occupation of the eg and $t_{2 g}$ molecular orbitals (see Figure 1 (c)). Due to the constant electron inelastic mean free path (IMFP, $\sim 1.5 \mathrm{~nm}^{40}$ ) and the approx. $7 \mathrm{~nm}$ size of our NPs, we obtain mainly signals from the outer NP layers, suggesting the existence of an $\mathrm{Oh}_{\mathrm{h}} \mathrm{Co}^{2+}$ and a $\mathrm{T}_{\mathrm{d}}$ $\mathrm{Co}^{2+}$ mixed shell or an $\mathrm{Oh}_{\mathrm{h}}{ }^{2+}$ core $-\mathrm{T}_{\mathrm{d}} \mathrm{Co}^{2+}$ shell structure, as proposed by Papaefthimiou et al. ${ }^{15}$ 
Under NAP conditions at a 4-mbar water atmosphere (in blue), we obtain an increased intensity for the 2p3p3p and the 2p3p3d PEY-XAS at $777.2 \mathrm{eV}$ (marked with A in Figure 2) as well as in the photon energy range between $779.6 \mathrm{eV}$ and $784.0 \mathrm{eV}$ (marked with $\mathbf{B}$ ). The increase at around $780.0 \mathrm{eV}$ photon energy is due to the enhancement of the $\mathrm{O}_{\mathrm{h}} \mathrm{Co}^{2+}$ signal, similarly to the increase at $777.2 \mathrm{eV}$. The extra intensity at energies beyond $782 \mathrm{eV}$ is a fingerprint of $\mathrm{Oh}_{\mathrm{h}} \mathrm{Co}^{3+}{ }^{12,41-44}$

We cannot exclude completely the formation of spinel $\mathrm{Co}_{3} \mathrm{O}_{4}$ or $\mathrm{CoOOH}$ at NAP conditions as suggested by the $\mathrm{Oh} \mathrm{Co}^{3+}$ signal, but we do not observe the expected associated decrease of the $\mathrm{Oh}$ $\mathrm{Co}^{2+}$ signal at $777.2 \mathrm{eV}$ in the PEY-XAS. ${ }^{12}$ The obtained spectral features of adsorbed water in Figure 2 (a) are less pronounced for the 2p3p3d PEY-XAS in Figure 2 (b), which is due to a higher delocalization probability of the d-electrons. During the few femtoseconds Co $2 p$ core lifetime, the core-excited electron in the $3 \mathrm{~d}$ valence band can delocalize with its surrounding, weakening the Auger decay channels involving a 3d electron. Thus, the PEY-XAS investigations suggest a mixedshell or core-shell structure of the $\mathrm{CoO}_{\mathrm{x}} \mathrm{NPs}$ at high vacuum pressure conditions and a waterinduced phase change of $\mathrm{T}_{\mathrm{d}} \mathrm{Co}^{2+}$ to $\mathrm{O}_{\mathrm{h}} \mathrm{Co}^{2+}$ and $\mathrm{Oh}_{\mathrm{h}} \mathrm{Co}^{3+}$.

Notably, the obtained extra intensities at near-ambient pressure go back to its initial state after having reestablished the high vacuum conditions, which indicates a reversible behavior. Figure 2 (b) shows the 2p3p3d PEY XAS at high vacuum before (black), during (blue), and after (brown) the investigations at NAP conditions. The 2p3p3d PEY-XA spectra under near-ambient conditions and afterwards at high vacuum conditions were measured for these spectra at the same sample spot.

There are two different transformations known for $\mathrm{T}_{\mathrm{d}} \mathrm{Co}^{2+}$ in contact with aqueous solutions: 1 ) an irreversible transformation of 'single-phased' $\mathrm{T}_{\mathrm{d}} \mathrm{Co}^{2+}$ towards $3 \mathrm{D}$ cross-linked $\mathrm{Co}^{2+/ 3+} \mathrm{O}_{\mathrm{x}}(\mathrm{OH})_{\mathrm{y}}$ by OER conditioning ${ }^{12}$ and 2) a reversible transformation of the $\mathrm{Td}_{d} \mathrm{Co}^{2+}$ in $\mathrm{Co}_{3} \mathrm{O}_{4}$ towards $\mathrm{CoOOH}$ under OER condition ${ }^{16,17,19,20}$. As we investigated the $\mathrm{CoO}_{\mathrm{x}}$ at open-circuit conditions, both 
changes should not take place. But as $\mathrm{T}_{\mathrm{d}} \mathrm{Co}^{2+}$ is thermodynamically not favored, an irreversible phase change similar to the findings during OER conditions is expected. Our results now suggest that the transformation of the $\mathrm{T}_{\mathrm{d}} \mathrm{Co}^{2+}$ phase in the presence of water reflects a possible intermediate state towards the further transformation during OER, occurring already at open-circuit conditions. 


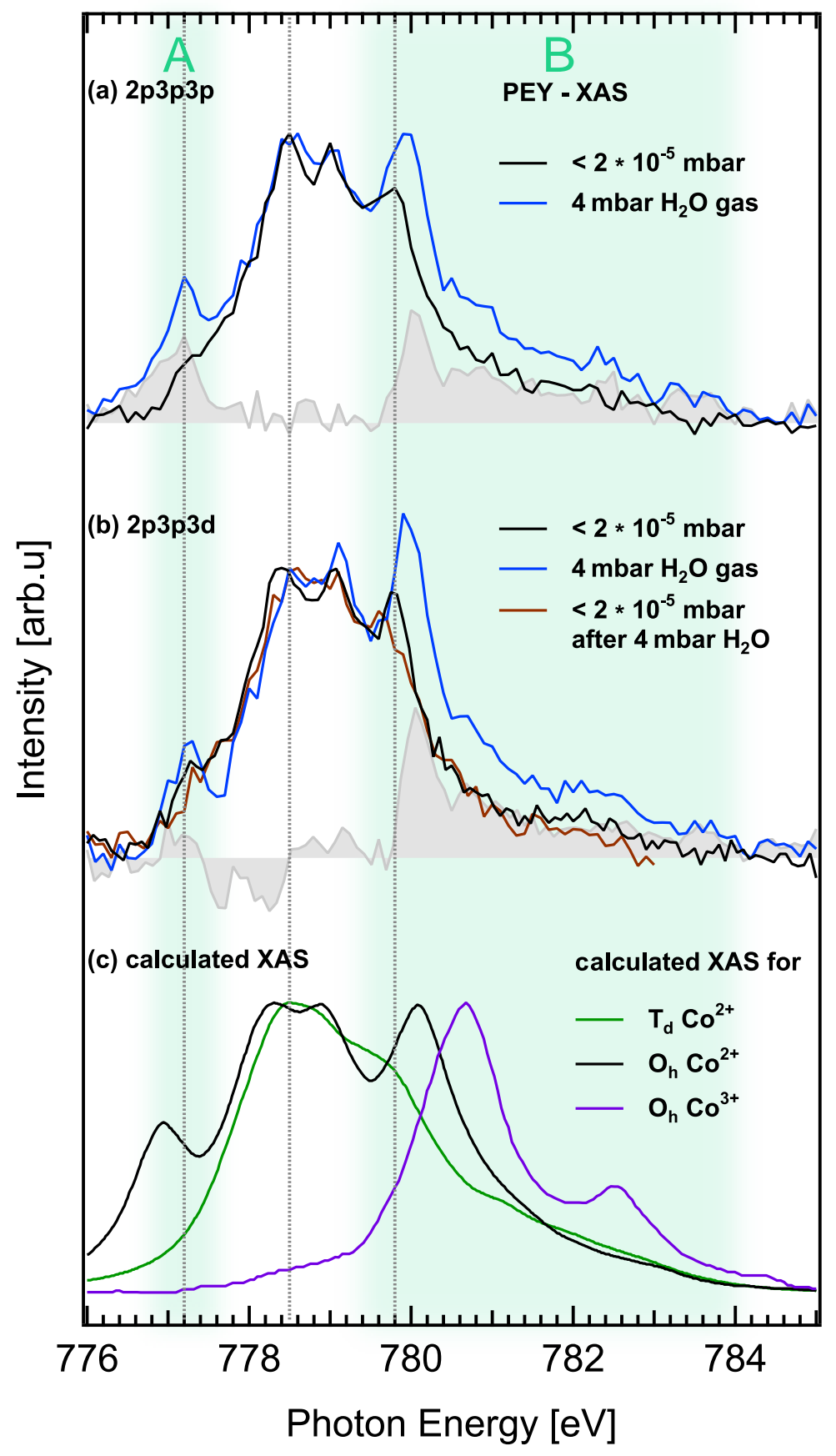

Figure 2. PEY-XAS of (a) 2p3p3p and (b) 2p3p3d of $\mathrm{CoO}_{x}$ NPs at high vacuum (black), at 4 mbar $\mathrm{H}_{2} \mathrm{O}$ atmosphere (blue) and again at high vacuum after the 4 mbar $\mathrm{H}_{2} \mathrm{O}$ measurement (brown). (c) Calculated XAS for $\mathrm{T}_{\mathrm{d}} \mathrm{Co}^{2+}, \mathrm{O}_{\mathrm{h}} \mathrm{Co}^{2+}$ und $\mathrm{O}_{\mathrm{h}} \mathrm{Co}^{3+} \cdot{ }^{12}$ Raw spectra were corrected with a linear background and normalized to the maximum intensity at $\mathrm{E}_{\mathrm{ph}}=778.1 \mathrm{eV}$. 
Resonant Auger spectra under near-ambient pressure conditions. Figure 3 shows the resonant Auger spectra at the cobalt Lз-edge under NAP conditions to reveal the subtle differences in electronic-structure during the NP-water interaction. The excitation energies used are $\mathrm{E}_{\mathrm{ph}}=772.0$ $\mathrm{eV}$ (off-resonant, black curve) and $\mathrm{E}_{\mathrm{ph}}=777.2 \mathrm{eV}$ (on-resonant, blue), enhancing only $\mathrm{O}_{\mathrm{h}} \mathrm{Co}^{2+}$ contributions of the NP in contact with liquid $\mathrm{H}_{2} \mathrm{O}$ (see Figure 2). In the resonant case, the spectator Auger decay causes four spectral increases: (1) the Co 2p3p3p Auger decay at a binding energy larger than $120 \mathrm{eV}$ (electron kinetic energy Ekin $<653 \mathrm{eV}$ ), (2) the Co 2p3s3d Auger decay at a binding energy larger than $100 \mathrm{eV}$ ( Ekin $<673 \mathrm{eV}$ ), (3) the Co 2p3p3d Auger decay at binding energies larger than $60 \mathrm{eV}$ ( Ekin $<713 \mathrm{eV}$ ) and (4) the Co 2p3d3d Auger decay at binding energies larger than $6 \mathrm{eV}\left(\mathrm{E}_{\mathrm{kin}}<769 \mathrm{eV}\right.$ ). Considering the low surface coverage of the $\mathrm{CoO}_{\mathrm{x}}$ NPs (approx. less than $1 \%$ ) the spectral increase using a resonant photon energy is significant and extends over a wide binding energy range, because of the large number of possible final states. The 3d-electrons of cobalt contain information of its valence electronic-structural environment, due to hybridization with its surrounding (mainly the lattice oxide), which also leads to a higher delocalization probability of the d-electron. Therefore, Auger decays involving d-electrons sense changes in the electronic environment, but are also weakened, as the core-excited electron in the $3 \mathrm{~d}$ valence band can delocalize with its surrounding during the Co 2p core lifetime of a few femtoseconds. Consequently, the Co 2p3d3d Auger decay in Figure 3 has the weakest intensity.

Besides the spectral increase of the spectator Auger decays, the participator Auger decay enhances the Co 3p signal as seen in the blue spectrum of Figure 3, with its maximum at Eв $=63.2$ $\mathrm{eV}$. Similar enhancements of the 3s at around $100 \mathrm{eV}^{45}$ are overlaid by the $\mathrm{Si} 2 \mathrm{p}$ and $\mathrm{SiO}_{\mathrm{x}} 2 \mathrm{p}$ orbitals. We included the calculated off-resonant and resonant 3p spectra by Tanaka et al. ${ }^{46}$ for a 
cluster composed of $\mathrm{Oh}_{\mathrm{h}} \mathrm{Co}^{2+}$ surrounded by six $\mathrm{O}^{2-}$ ions for comparison. They used a cluster model with full multiplet splitting for their calculations that matches qualitatively our experimental data. ${ }^{46}$ Although these modeled values do not include a liquid $\mathrm{H}_{2} \mathrm{O}$ surrounding, they still predict the obtained data well, except for the spectator Auger spectral region around $70 \mathrm{eV}$.

As $99 \%$ of the sample surface consists of the $\mathrm{SiO}_{\mathrm{x}} / \mathrm{Si}(111)$ substrate, the spectra in Figure 3 display strong $\mathrm{SiO}_{x}$ features, namely the $\mathrm{SiO}_{x} 2 \mathrm{p}(104.7 \mathrm{eV})$, the $\mathrm{Si} 2 \mathrm{p} 3 / 2(99.4 \mathrm{eV})$ and the 2p1/2 $(100.0 \mathrm{eV}))$. At NAP conditions the $\mathrm{SiO}_{\mathrm{x}} \mathrm{O} 2 \mathrm{~s}(27.5 \mathrm{eV})$ and $\mathrm{SiO}_{\mathrm{x}} / \mathrm{Si}(111)$ valence band structure are superimposed by $\mathrm{H}_{2} \mathrm{O}$ gas and liquid orbitals. Literature values for the $\mathrm{H}_{2} \mathrm{O}$ gas peak positions are highlighted in Figure $3 .{ }^{47}$ A detailed analysis of the $\mathrm{SiO}_{x} / \mathrm{Si}(111)$ substrate using NAP-XPS can be found in Figure SI-2. Due to the low surface coverage of the $\mathrm{CoO}_{\mathrm{x}} \mathrm{NPs}$, off-resonant $\mathrm{O}$ 1s and O 2s spectra contain hardly any contributions from either $\mathrm{CoO}_{\mathrm{x}} \mathrm{NP}$ lattice oxide or from adsorbed $\mathrm{H}_{2} \mathrm{O}$ and possible terminated $\mathrm{OH}$-groups on the NP surface. 


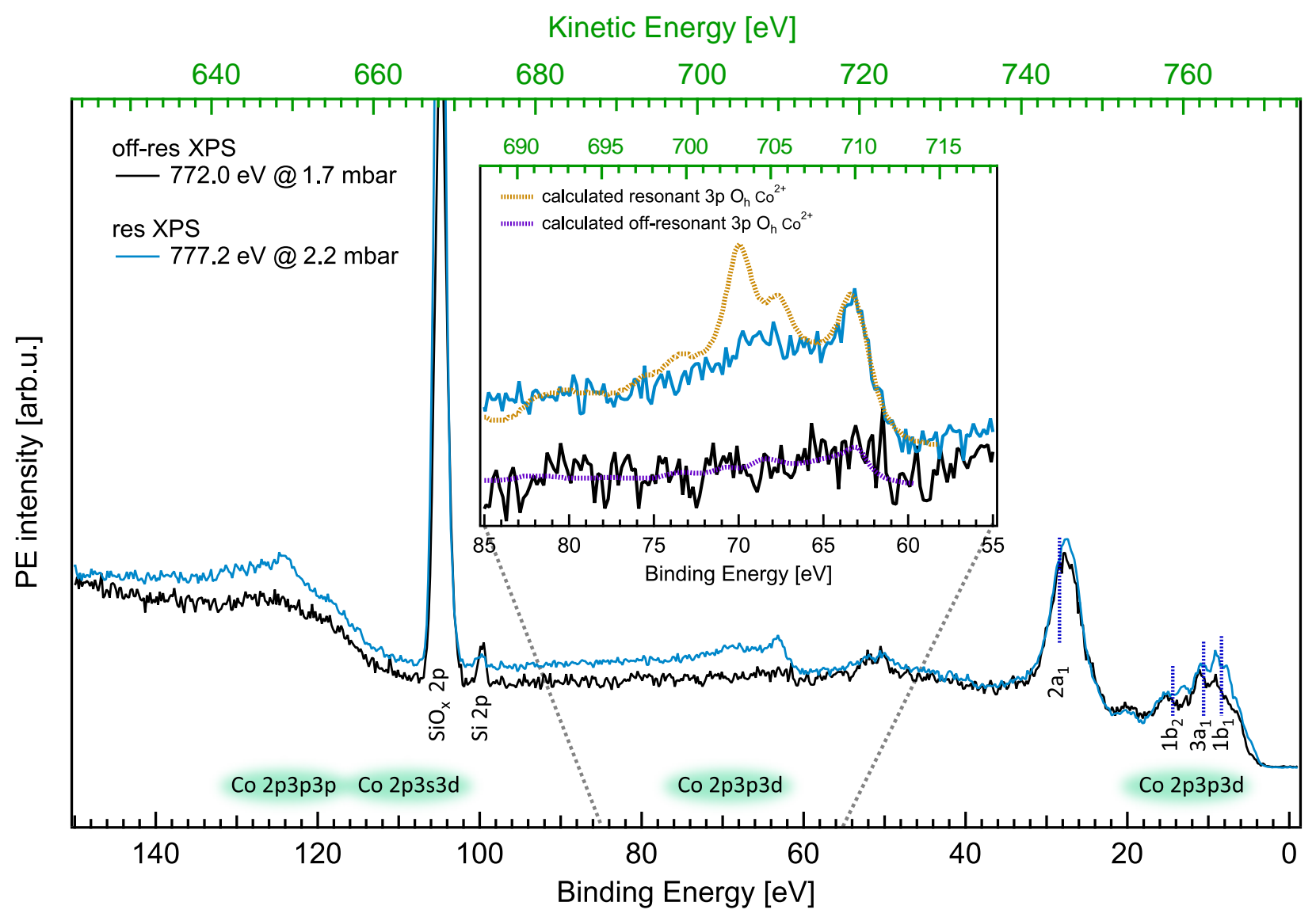

Figure 3. Co 2p $\rightarrow$ 3d on-resonant (777.2 eV, blue curve) and off-resonant (772.0 eV, black curve) photoelectron spectra of $\mathrm{CoO}_{\mathrm{x}} \mathrm{NP}$ on a $\mathrm{SiO}_{\mathrm{x}} / \mathrm{Si}(111)$ substrate, measured at 2 mbar pressure. In resonance, the Co 2p3p3p, Co 2p3s3d, Co 2p3p3d and Co 2p3d3d Auger decay are visible. Offand on-resonant spectra are dominated by $\mathrm{SiO}_{\mathrm{x}}$ and $\mathrm{Si}$ signals, and also contribution from gas and liquid water are present in the valence band. The binding energies of the water molecular orbitals are marked. ${ }^{47}$ Inset: Zoom-in of Co 2p3p3d Auger decay signal together with calculated onresonant (yellow) and off-resonant spectra (purple) of $\mathrm{Oh}_{\mathrm{h}} \mathrm{Co}^{2+} \cdot{ }^{46}$ 
Resonant-PES at high vacuum vs near-ambient pressure (valence band). Additional studies on the participator Auger decay, measured at defined photon energies, reveal the enhanced 3d spectrum, from which we can derive the different Co-species present in the NP surface. Several pairs of off-and on-resonant spectra were measured, changing to a new sample spot when measuring a new pair at high vacuum and near-ambient pressure conditions. The difference 'onresonant spectrum’ minus ‘off-resonant spectrum’ (grey) for several selected photon energies ('offresonant': $772.0 \mathrm{eV}$ and 'on-resonant': $777.2 \mathrm{eV}, 778.5 \mathrm{eV}$ and $779.8 \mathrm{eV}$; marked at the integrated PEY-XAS spectra in the insets) are plotted in Figure 4A at high vacuum, and in Figure 4B at nearambient pressure conditions, as well as in Figure SI-3. Positive values in the difference spectra reveal an enhanced Co 3d signal and 2p3d3d spectator Auger decay. As previously discussed, the valence spectra measured at high vacuum conditions (Figure SI-4) are dominated by the $\mathrm{SiO}_{\mathrm{x}} / \mathrm{Si}(111)$ contributions. Using the PEY-XAS results, one expects the resonant enhancement at high vacuum to be a superposition of $\mathrm{T}_{\mathrm{d}} \mathrm{Co}^{2+} 3 \mathrm{~d}$ and $\mathrm{O}_{\mathrm{h}} \mathrm{Co}^{2+} 3 \mathrm{~d}$ signals. At the lowest resonant photon energy, the calculated XAS predicts a strong $\mathrm{Oh}_{\mathrm{ho}}{ }^{2+}$ feature which absence indicates a stronger $\mathrm{T}_{\mathrm{d}} \mathrm{Co}^{2+} \mathrm{NP}$ component and PES signal. Additionally, the difference spectra at high vacuum conditions do not resemble the calculated $\mathrm{Oh} \mathrm{Co}^{2+} 3 \mathrm{~d}$ resonant spectra as shown in Figure 4b, but can be emulated when we include calculated final states for $\mathrm{Td}_{\mathrm{d}} \mathrm{Co}^{2+}$ (green). ${ }^{48}$

The valence spectra measured at NAP conditions (Figure 4b) are dominated by $\mathrm{H}_{2} \mathrm{O}$ gas and liquid contributions. For the difference at near-ambient pressure conditions we append the calculated $\mathrm{O}_{\mathrm{h}} \mathrm{Co}^{2+} 3 \mathrm{~d}$ resonant spectra by Tanaka et al. (orange) and calculated final states for $\mathrm{O}_{\mathrm{h}}$ $\mathrm{Co}^{3+}$ (purple) using ligand-field theory by Jugnet et $a l .{ }^{46,48}$ The calculated spectra resemble our data, especially for lower binding energies at a photon energy of $777.2 \mathrm{eV}$. At higher excitation energies a signal contribution around $4.9 \mathrm{eV}$ arises by the ${ }^{2} \mathrm{~T}_{2 \mathrm{~g}}$ final state of $\mathrm{Oh}_{\mathrm{h}} \mathrm{Co}^{3+}$ (purple stick). 
The measured signal in Figure $4 \mathrm{~b}$ at binding energies between $5-10 \mathrm{eV}$ is lower than the calculated spectra. $^{49}$

These findings confirm that: i) at high vacuum conditions the main NP component is $\mathrm{T}_{\mathrm{d}} \mathrm{Co}^{2+}$, and ii) a phase transformation from the $\mathrm{T}_{\mathrm{d}} \mathrm{Co}^{2+} \mathrm{NP}$ phase to $\mathrm{O}_{\mathrm{h}} \mathrm{Co}^{2+}$ and $\mathrm{O}_{h} \mathrm{Co}^{3+}$ occurs under NAP conditions, as it is also revealed by the PEY-XA spectra (Figure 2).

$\mathrm{X}$-ray radiation effects and sample contamination. Not yet mentioned is the influence of radiation and contamination affecting the sample. Despite differently noted, we changed between PEY-XAS and resonant XPS measurements regularly the spot to prevent long exposure radiation damage effects. For the PEY-XAS measurements we also lowered the photon flux by one order of magnitude compared to the resXPS measurements. Contamination of our samples by hydrocarbons is inevitable due to an ex situ preparation. The existence of oxygen species beside $\mathrm{SiO}_{\mathrm{x}}$ is revealed by the O 1s and C 1s XPS (Figure SI-4). Since we use resonant photon energies, the Co $2 \mathrm{p} \rightarrow 3 \mathrm{~d}$ PEY-XA spectra are dominated by cobalt signals. To ensure this for the resXPS, we performed offresonant PES before every on-resonant measurement. Positive values for the difference 'onresonant spectrum’ minus 'off-resonant' spectrum refer solely to cobalt enhancements. Negative values for the difference are not a result of the resonant PES itself, but of a continuous reduction of the signal, most likely due to a continuously increasing surface contamination of carbon species, $\mathrm{CO}_{\mathrm{x}} \mathrm{H}_{\mathrm{y}}$. 


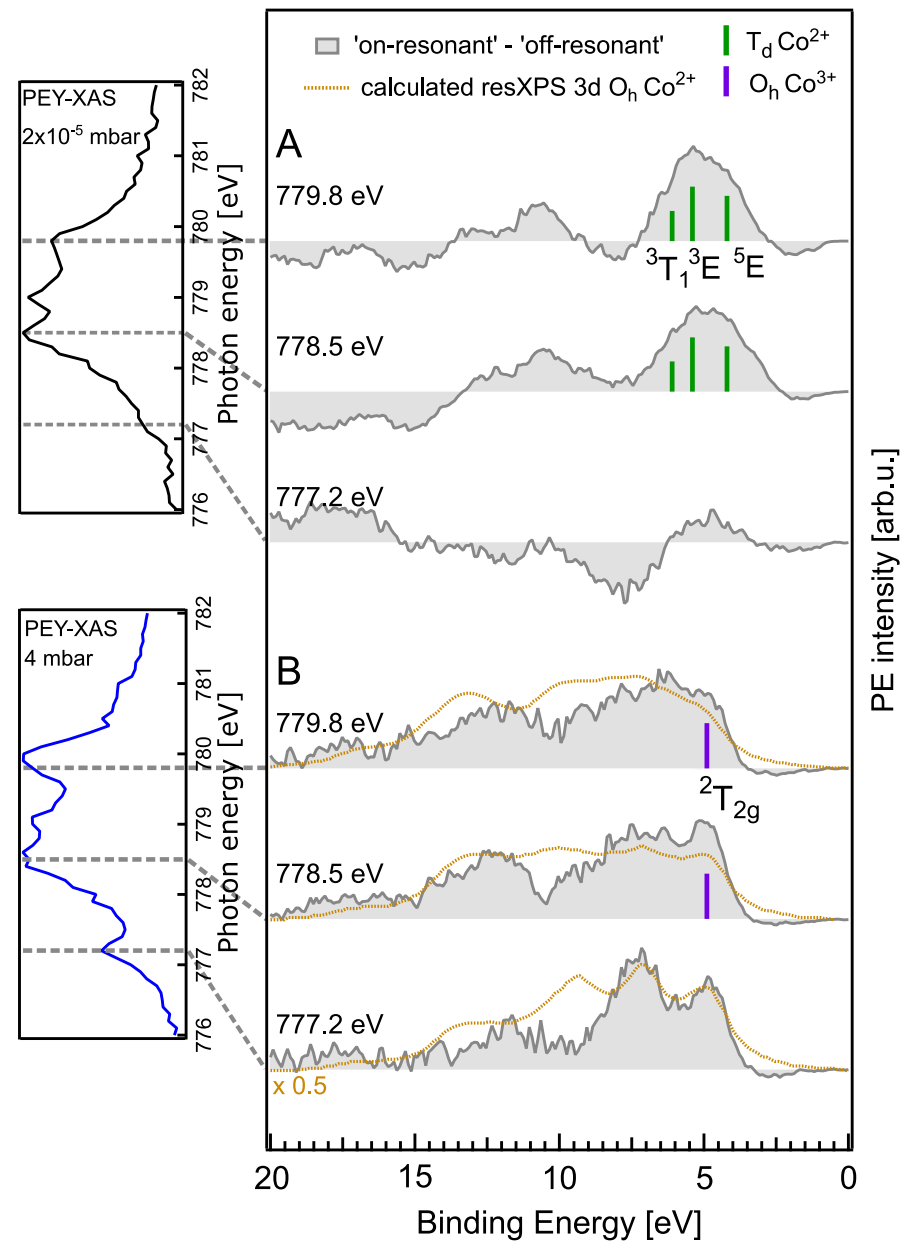

Figure 4. Differences of 'on-resonant' spectrum (777.2 eV, $778.5 \mathrm{eV}$ and $779.8 \mathrm{eV})$ minus 'off-resonant' spectrum (772.0 eV) XPS taken at (A) high vacuum, and at (B) NAP conditions. Included are calculated 3d resonant XPS of $\mathrm{Oh}_{\mathrm{h}}{ }^{2+}$ and calculated $3 \mathrm{~d}$ final states of $\mathrm{T}_{\mathrm{d}} \mathrm{Co}^{2+}$ and $\mathrm{Oh}_{\mathrm{Co}}{ }^{3+} \cdot{ }^{46,48}$ The boxes on the left hand side display the 2p3p3p PEY-XAS measurements from Figure 3. 


\section{CONCLUSION}

We used NAP-XPS to identify the phase changes in size-selected $\mathrm{CoO}_{\mathrm{x}} \mathrm{NPs}$ on a $\mathrm{SiO} / \mathrm{Si}(111)$ substrate. Under high vacuum conditions these NPs consist of an $\mathrm{Oh} \mathrm{Co}^{2+}$ and a $\mathrm{T}_{\mathrm{d}} \mathrm{Co}^{2+}$ phase, with a proposed $\mathrm{T}_{\mathrm{d}}$ shell. ${ }^{15}$ In a water atmosphere ( $\left.\sim 4 \mathrm{mbar}\right)$, the composition is altered to an $\mathrm{O}_{\mathrm{h}} \mathrm{Co}^{3+}$ and an $\mathrm{Oh} \mathrm{Co}^{2+}$ phase. When reapplying high vacuum conditions, and after water evaporation, the previous cobalt oxide composition is reestablished. We observe that water changes the shell of the NPs, resulting in the reversible destabilization of the metastable $\mathrm{T}_{\mathrm{d}} \mathrm{Co}^{2+}$ phase and in the formation of $\mathrm{O}_{\mathrm{h}} \mathrm{Co}^{2+}$ and oxidized $\mathrm{O}_{\mathrm{h}} \mathrm{Co}^{3+}$. Since we operate our experiments without applied an oxidizing bias, our measurements reveal an intermediate state. We cannot completely exclude a possible formation of $\mathrm{CoOOH}$, however, we do not observe the necessary accompanied decrease of the $\mathrm{O}_{\mathrm{h}}$ $\mathrm{Co}^{2+}$ signal in the PEY-XA spectra. Using resonant XPS we could also spectroscopically reveal the cobalt oxide valence band of $\mathrm{Oh}_{\mathrm{h}} \mathrm{Co}^{2+}+\mathrm{T}_{\mathrm{d}} \mathrm{Co}^{2+}$ at high vacuum and of $\mathrm{Oh}_{\mathrm{h}} \mathrm{Co}^{3+}+\mathrm{O}_{\mathrm{h}} \mathrm{Co}^{2+}$ at nearambient pressure.

The next logical step would be to carry out the resonant XPS experiments under operando conditions. This requires a different approach, e.g. the use of special micro-electrochemical cells with graphene-covered holey-membranes. ${ }^{50,51}$ The few monolayer of graphene act as the working electrode and the carrier for the deposited $\mathrm{CoO}_{x}$ nanoparticles. These experiments are currently planned.

Overall, we showed that a water-induced phase transformation affects the $\mathrm{CoO}_{\mathrm{x}} \mathrm{NP}$ catalyst differently than voltage-induced changes in an aqueous electrolyte, which is relevant for our understanding of the interaction of Co ions with water at the atomic level. 


\section{METHODS}

Sample preparation and characterization. The $\mathrm{CoO}_{x} \mathrm{NP}$ catalyst was prepared by the inverse micelle encapsulation route as described elsewhere. ${ }^{52}$ In short, $\mathrm{CoCl}_{2}$ and poly(styrene-b-2vinypyridine) di-block copolymers were dissolved in toluene and the inverse micelles were dipcoated on an oxide-terminated $\mathrm{Si}(111)$ wafer. Subsequently, an $\mathrm{O}_{2}$ plasma (20 W, 400 mTorr, 20 min) was applied to remove the polymer. Atomic force microscopy (Bruker MultiMode 8, tapping mode) was used to determine the NP height $(7.0 \pm 2.0 \mathrm{~nm})$ and the average nearest neighbor distance (75 nm), see Figure 1 (b) and S1.

Photoemission measurements. The XPS measurements were carried out at the U49/2-PGM-1 beamline $^{53}$ located at the synchrotron radiation facility BESSY II in Berlin, Germany, using our NAP Sol3PES experimental setup. ${ }^{54}$ The U49/2 beamline provides high-brilliant soft X-ray light up to a photon energy of $\mathrm{E}_{\mathrm{ph}}=1400 \mathrm{eV}$, enough to core-ionize water and also to excite Co $2 \mathrm{p}$ electrons into the valence band. The Sol${ }^{3}$ PES experimental setup is equipped with a Scienta Omicron R4000 HIPP-2 hemispherical electron analyzer and is capable of detecting photoelectrons from samples inside our vacuum chamber at elevated pressures of up to 20 mbar water vapor. Since the detection screen and the multichannel plate of the electron-analyzer require high vacuum conditions $\left(<10^{-8} \mathrm{mbar}\right)$, there are three differential pumping sections, each consisting of a pinhole and two turbo molecular pumps, to separate the detector unit from the experimental chamber. A similar differential pumping scheme is used to deal with the pressure difference between the experimental chamber and the ultra-high vacuum $\left(<10^{-9} \mathrm{mbar}\right)$ inside the beamline. The distance between the electron analyzer entrance pinhole and the focal point of the soft X-ray beam is shorter than $500 \mu \mathrm{m}$, minimizing electron scattering at the water vapor in the chamber that causes an 
attenuated electron signal. A detailed description of the SOL ${ }^{3}$ PES setup and its characteristics can be found elsewhere. ${ }^{54}$ During our measurements the angle between the polarization axis of the incoming soft $\mathrm{X}$-ray and the electron analyzer was $54,7^{\circ}$ (magic-angle geometry) to avoid any photoelectron angular distribution effects. The X-ray photoelectron spectra were energy calibrated using the Si 2p3/2 peak, with a $99.4 \mathrm{eV}$ binding energy, and the spectra were normalized for comparison to the background intensity near $35 \mathrm{eV}$ binding energy. ${ }^{55}$

Resonant photoelectron spectroscopy. Our resonant photoelectron spectroscopy measurements focus on three specific Auger decay channels, 2p3p3p, 2p3p3d \& 2p3d3d, and presented in Figure 1 (c).

In general, the excitation of a core electron into an unoccupied state (step 1 - black arrow), leads to a spectator Auger decay, where the hole is refilled by another energetically higher lying electron (step 2 - brown arrow) and the excess energy is used to kick out an electron of the sample (step 3 - grey arrow). ${ }^{34,54}$ A second resonant Auger channel is the participator Auger decay. Here, the first step is an excitation of a core-level electron into the valence band $(2 p \rightarrow 3 d)$ similar to the spectator Auger decay. However, in the second step the excited electron itself refills the core hole and transfers its energy to another bound electron. As a consequence, the emitted Auger electron (step 3) will have the same kinetic energy as a directly emitted photoelectron, leading to a constructive interference of two identical final states enhancing the measured signals. ${ }^{34,46}$

Partial electron yield $x$-ray absorption spectrum (PEY-XAS). Plotting the integral of a specific Auger decay channel signal as a function of the photon energy generates the respective (2p3p3p \& 2p3p3d) partial electron yield x-ray absorption spectrum (PEY-XAS). ${ }^{32,34,56}$ These useful spectra exhibit signatures characteristic of the cobalt oxidation state and its coordination structure. ${ }^{12,15,30,31,41-44,57}$ 
Near-ambient pressure. To create a 4-mbar water vapor environment we connected a test tube filled with Milli-Q water (degassed by two freeze-pump-thaw cycles) to the vacuum chamber. A needle valve is used to set the required $\mathrm{H}_{2} \mathrm{O}$ gas flow into the chamber. To create a defined chamber pressure, the pumping flow rate is controlled with a motorized gas regulating valve (Pfeiffer EVR 116), which is managed by a proportional-integral-derivative controller (Pfeiffer RVC300 pressure gauge). Additionally, our sample holder consists of a brass block with pipes flushed with cold liquid ethanol, temperature-controlled by a chiller (Julabo F12-ED). The relative humidity in our chamber was calculated to be $70 \%$, which translates into an adsorbed water layer thickness between 1.5 monolayer ${ }^{55}$ and 5 monolayers ${ }^{58}$. ASSOCIATED CONTENT

Supporting Information. Atomic force microscopy image of the sample. NAP-XPS of SiOx/Si(111) substrate. 'On-resonant' and 'off-resonant' spectra used to obtain the difference spectra in Figure 4 and additional O1s and C1s XP spectra.

The following file is available free of charge via the Internet at http://pubs.acs.org.

$$
\text { SI.pdf }
$$

\section{AUTHOR INFORMATION}

Corresponding Author

Email: Robert.seidel@helmholtz-berlin.de (RS)

\section{Author Contributions}


RS, $\mathrm{AB}, \mathrm{GW}, \mathrm{DH}$ performed the measurement at the BESSY II synchrotron. $\mathrm{MB}, \mathrm{AB}$ and $\mathrm{BRC}$ prepared the samples. RS and DH wrote the manuscript, with comments from all authors.

\section{ACKNOWLEDGMENT}

DH, GW, and RS acknowledge funding from the Deutsche Forschungsgemeinschaft (DFG, German Research Foundation) through an Emmy-Noether grant (SE 2253/3-1). AB and BRC acknowledge finantial support from DFG- project no. 388390466 - TRR 247, subproject A4. All authors thank the HZB staff for support during the beamtimes at BESSY II.

\section{REFERENCES}

(1) Wang, J.; Cui, W.; Liu, Q.; Xing, Z.; Asiri, A. M.; Sun, X. Recent Progress in Cobalt-Based Heterogeneous Catalysts for Electrochemical Water Splitting. Adv. Mater. 2016, 28, 215-230.

(2) Yan, Y.; Xia, B. Y.; Zhao, B.; Wang, X. A Review on Noble-Metal-Free Bifunctional Heterogeneous Catalysts for Overall Electrochemical Water Splitting. J. Mater. Chem. A. 2016, 4, 17587-17603.

(3) Wu, L.; Li, Q.; Wu, C. H.; Zhu, H.; Mendoza-Garcia, A.; Shen, B.; Guo, J.; Sun, S. Stable Cobalt Nanoparticles and Their Monolayer Array as an Efficient Electrocatalyst for Oxygen Evolution Reaction. J. Am. Chem. Soc. 2015, 137, 7071-7074.

(4) Chou, N. H.; Ross, P. N.; Bell, A. T.; Tilley, T. D. Comparison of Cobalt-Based Nanoparticles as Electrocatalysts for Water Oxidation. ChemSusChem 2011, 4, 1566-1569. 
(5) Zhang, M.; De Respinis, M.; Frei, H. Time-Resolved Observations of Water Oxidation Intermediates on a Cobalt Oxide Nanoparticle Catalyst. Nat. Chem. 2014, 6, 362-367.

(6) Zhang, Y.; Rosen, J.; Hutchings, G. S.; Jiao, F. Enhancing Photocatalytic Oxygen Evolution Activity of Cobalt-Based Spinel Nanoparticles. Catal. Today 2014, 225, 171-176.

(7) Liao, L.; Zhang, Q.; Su, Z.; Zhao, Z.; Wang, Y.; Li, Y.; Lu, X.; Wei, D.; Feng, G.; Yu, Q.; Cai, X.; Zhao, J.; Ren, Z.; Fang, H.; Robles-Hernandez, F.; Baldelli, S.; Bao, J. Efficient Solar Water-Splitting Using a Nanocrystalline CoO Photocatalyst. Nat. Nanotechnol. 2014, 9, 69-73.

(8) Jiao, F.; Frei, H. Nanostructured Cobalt and Manganese Oxide Clusters as Efficient Water Oxidation Catalysts. Energy Environ. Sci. 2010, 3, 1018-1027.

(9) Esswein, A. J.; Mcmurdo, M. J.; Ross, P. N.; Bell, A. T.; Tilley, T. D. Size-Dependent Activity of Co3O4 Nanoparticle Anodes for Alkaline Water Electrolysis. J. Phys. Chem. C 2009, 113, 15068-15072.

(10) Grzelczak, M.; Zhang, J.; Pfrommer, J.; Hartmann, J.; Driess, M.; Antonietti, M.; Wang, X. Electro- and Photochemical Water Oxidation on Ligand-Free Co $3 \mathrm{O} 4$ Nanoparticles with Tunable Sizes. ACS Catal. 2013, 3, 383-388.

(11) Zhuang, Z.; Sheng, W.; Yan, Y. Synthesis of Monodispere Au@Co3O4 Core-Shell Nanocrystals and Their Enhanced Catalytic Activity for Oxygen Evolution Reaction. Adv. Mater. 2014, 26, 3950-3955.

(12) Bergmann, A.; Jones, T. E.; Martinez Moreno, E.; Teschner, D.; Chernev, P.; Gliech, M.; Reier, T.; Dau, H.; Strasser, P. Unified Structural Motifs of the Catalytically Active State of 
Co(Oxyhydr)Oxides during the Electrochemical Oxygen Evolution Reaction. Nat. Catal. 2018, 1, 711-719.

(13) Chen, J.; Wu, X.; Selloni, A. Electronic Structure and Bonding Properties of Cobalt Oxide in the Spinel Structure. Phys. Rev. B - Condens. Matter Mater. Phys. 2011, 83, 1-7.

(14) Risbud, A. S.; Snedeker, L. P.; Elcombe, M. M.; Cheetham, A. K.; Seshadri, R. Wurtzite CoO. Chem. Mater. 2005, 17, 834-838.

(15) Papaefthimiou, V.; Dintzer, T.; Dupuis, V.; Tamion, A.; Tournus, F.; Hillion, A.; Teschner, D.; Hävecker, M.; Knop-Gericke, A.; Schlögl, R.; Zafeiratos, S. Nontrivial Redox Behavior of Nanosized Cobalt: New Insights from Ambient Pressure X-Ray Photoelectron and Absorption Spectroscopies. ACS Nano 2011, 5, 2182-2190.

(16) Wang, H. Y.; Hung, S. F.; Hsu, Y. Y.; Zhang, L.; Miao, J.; Chan, T. S.; Xiong, Q.; Liu, B. In Situ Spectroscopic Identification of $\mu$-OO Bridging on Spinel Co3O4 Water Oxidation Electrocatalyst. J. Phys. Chem. Lett. 2016, 7, 4847-4853.

(17) Wang, H. Y.; Hung, S. F.; Chen, H. Y.; Chan, T. S.; Chen, H. M.; Liu, B. In Operando Identification of Geometrical-Site-Dependent Water Oxidation Activity of Spinel Co3O4. J. Am. Chem. Soc. 2016, 138, 36-39.

(18) Bajdich, M.; García-Mota, M.; Vojvodic, A.; Nørskov, J. K.; Bell, A. T. Theoretical Investigation of the Activity of Cobalt Oxides for the Electrochemical Oxidation of Water. J. Am. Chem. Soc. 2013, 135, 13521-13530. 
(19) Bergmann, A.; Martinez-Moreno, E.; Teschner, D.; Chernev, P.; Gliech, M.; De Araújo, J. F.; Reier, T.; Dau, H.; Strasser, P. Reversible Amorphization and the Catalytically Active State of Crystalline Co3O4 during Oxygen Evolution. Nat. Commun. 2015, 6, 1-9.

(20) Tung, C. W.; Hsu, Y. Y.; Shen, Y. P.; Zheng, Y.; Chan, T. S.; Sheu, H. S.; Cheng, Y. C.; Chen, H. M. Reversible Adapting Layer Produces Robust Single-Crystal Electrocatalyst for Oxygen Evolution. Nat. Commun. 2015, 6, 1-9.

(21) Favaro, M.; Yang, J.; Nappini, S.; Magnano, E.; Toma, F. M.; Crumlin, E. J.; Yano, J.; Sharp, I. D. Understanding the Oxygen Evolution Reaction Mechanism on CoOx Using Operando Ambient-Pressure X-Ray Photoelectron Spectroscopy. J. Am. Chem. Soc. 2017, 139, 8960-8970.

(22) Liu, J.; Bao, H.; Zhang, B.; Hua, Q.; Shang, M.; Wang, J.; Jiang, L. Geometric Occupancy and Oxidation State Requirements of Cations in Cobalt Oxides for Oxygen Reduction Reaction. ACS Appl. Mater. Interfaces 2019, 11, 12525-12534.

(23) Grimes, R. W.; Lagerlof, K. P. D. Polymorphs of Cobalt Oxide. J. Am. Ceram. Soc. 1991, 74, 270-273.

(24) Meyerheim, H. L.; Tusche, C.; Ernst, A.; Ostanin, S.; Maznichenko, I. V.; Mohseni, K.; Jedrecy, N.; Zegenhagen, J.; Roy, J.; Mertig, I.; Kirschner, J. Wurtzite-Type CoO Nanocrystals in Ultrathin ZnCoO Films. Phys. Rev. Lett. 2009, 102, 1-4.

(25) Nam, K. M.; Shim, J. H.; Han, D. W.; Kwon, H. S.; Kang, Y. M.; Li, Y.; Song, H.; Seo, W. S.; Park, J. T. Syntheses and Characterization of Wurtzite CoO, Rocksalt CoO, and Spinel Co3O4 Nanocrystals: Their Interconversion and Tuning of Phase and Morphology. Chem. Mater. 2010, 22, 4446-4454. 
(26) Seo, W. S.; Shim, J. H.; Oh, S. J.; Lee, E. K.; Hur, N. H.; Park, J. T. Phase- and SizeControlled Synthesis of Hexagonal and Cubic CoO Nanocrystals. J. Am. Chem. Soc. 2005, 127, 6188-6189.

(27) Meyer, W.; Hock, D.; Biedermann, K.; Gubo, M.; Müller, S.; Hammer, L.; Heinz, K. Coexistence of Rocksalt and Wurtzite Structure in Nanosized CoO Films. Phys. Rev. Lett. 2008, $101,1-4$.

(28) Meyer, W.; Biedermann, K.; Gubo, M.; Hammer, L.; Heinz, K. Superstructure in the Termination of $\mathrm{CoO}(111)$ Surfaces: Low-Energy Electron Diffraction and Scanning Tunneling Microscopy. Phys. Rev. B - Condens. Matter Mater. Phys. 2009, 79, 1-4.

(29) Lukashuk, L.; Föttinger, K.; Kolar, E.; Rameshan, C.; Teschner, D.; Hävecker, M.; KnopGericke, A.; Yigit, N.; Li, H.; McDermott, E.; Stöger-Pollach, M.; Rupprechter, G. Operando XAS and NAP-XPS Studies of Preferential CO Oxidation on Co3O4 and CeO2-Co3O4 Catalysts. J. Catal. 2016, 344, 1-15.

(30) Papaefthimiou, V.; Dintzer, T.; Dupuis, V.; Tamion, A.; Tournus, F.; Teschner, D.; Hävecker, M.; Knop-Gericke, A.; Schlögl, R.; Zafeiratos, S. When a Metastable Oxide Stabilizes at the Nanoscale: Wurtzite CoO Formation upon Dealloying of PtCo Nanoparticles. J. Phys. Chem. Lett. 2011, 2, 900-904.

(31) Turczyniak, S.; Luo, W.; Papaefthimiou, V.; Ramgir, N. S.; Haevecker, M.; MacHocki, A.; Zafeiratos, S. A Comparative Ambient Pressure X-Ray Photoelectron and Absorption Spectroscopy Study of Various Cobalt-Based Catalysts in Reactive Atmospheres. Top. Catal. 2016, 59, 532-542. 
(32) Seidel, R.; Ghadimi, S.; Lange, K. M.; Bonhommeau, S.; Soldatov, M. A.; Golnak, R.;

Kothe, A.; Könnecke, R.; Soldatov, A.; Thürmer, S.; Winter, B.; Aziz, E. F. Origin of DarkChannel X-Ray Fluorescence from Transition-Metal Ions in Water. J. Am. Chem. Soc. 2012, 134, $1600-1605$.

(33) Tian, L.; Zhu, J. L.; Chen, L.; An, B.; Liu, Q. Q.; Huang, K. L. Synthesis and Characterization of $\alpha$-Cobalt Hydroxide Nanobelts. J. Nanoparticle Res. 2011, 13, 3483-3488.

(34) Lalithambika, S. S. N.; Atak, K.; Seidel, R.; Neubauer, A.; Brandenburg, T.; Xiao, J.; Winter, B.; Aziz, E. F. Chemical Bonding in Aqueous Hexacyano Cobaltate from Photon- and Electron-Detection Perspectives. Sci. Rep. 2017, 7, 1-13.

(35) Seidel, R.; Ghadimi, S.; Lange, K. M.; Bonhommeau, S.; Soldatov, M. A.; Golnak, R.; Kothe, A.; Könnecke, R.; Soldatov, A.; Thürmer, S.; Winter, B.; Aziz, E. F. Origin of DarkChannel X-Ray Fluorescence from Transition-Metal Ions in Water. J. Am. Chem. Soc. 2012, 134, $1600-1605$.

(36) Yamamoto, S.; Bluhm, H.; Andersson, K.; Ketteler, G.; Ogasawara, H.; Salmeron, M.; Nilsson, A. In Situ X-Ray Photoelectron Spectroscopy Studies of Water on Metals and Oxides at Ambient Conditions. J. Phys. Condens. Matter 2008, 20, 1-14.

(37) Kendelewicz, T.; Kaya, S.; Newberg, J. T.; Bluhm, H.; Mulakaluri, N.; Moritz, W.; Scheffler, M.; Nilsson, A.; Pentcheva, R.; Brown, G. E. Density Functional Theory Study on the Interaction of CO 2 with Fe 3 O 4 (111) Surface. Appl. Surf. Sci. 2016, 378, 270-276.

(38) Yamamoto, S.; Kendelewicz, T.; Newberg, J. T.; Ketteler, G.; Starr, D. E.; Mysak, E. R.; Andersson, K. J.; Ogasawara, H.; Bluhm, H.; Salmeron, M.; Brown, G. E.; Nilsson, A. Water 
Adsorption on $\alpha-\mathrm{Fe} 2 \mathrm{O} 3$ (0001) at near Ambient Conditions. J. Phys. Chem. C 2010, 114, 22562266.

(39) Uldry, A.; Vernay, F.; Delley, B. Systematic Computation of Crystal-Field Multiplets for x-Ray Core Spectroscopies. Phys. Rev. B - Condens. Matter Mater. Phys. 2012, 85, 1-14.

(40) Standard Reference Data, N. NIST Standard Reference Database 71. 1999. https://doi.org/10.18434/T48C78.

(41) Bazin, D.; Kovács, I.; Guczi, L.; Parent, P.; Laffon, C.; De Groot, F.; Ducreux, O.; Lynch, J. Genesis of Co/SiO2 Catalysts: XAS Study at the Cobalt LIII,II Absorption Edges. J. Catal. 2000, 189, 456-462.

(42) Hibberd, A. M.; Doan, H. Q.; Glass, E. N.; De Groot, F. M. F.; Hill, C. L.; Cuk, T. Co Polyoxometalates and a Co3O4 Thin Film Investigated by L-Edge X-Ray Absorption Spectroscopy. J. Phys. Chem. C 2015, 119, 4173-4179.

(43) Morales, F.; De Groot, F. M. F.; Glatzel, P.; Kleimenov, E.; Bluhm, H.; Hävecker, M.; Knop-Gericke, A.; Weckhuysen, B. M. In Situ X-Ray Absorption of Co/Mn/TiO 2 Catalysts for Fischer-Tropsch Synthesis. J. Phys. Chem. B 2004, 108, 16201-16207.

(44) Zafeiratos, S.; Dintzer, T.; Teschner, D.; Blume, R.; Hävecker, M.; Knop-Gericke, A.; Schlögl, R. Methanol Oxidation over Model Cobalt Catalysts: Influence of the Cobalt Oxidation State on the Reactivity. J. Catal. 2010, 269, 309-317.

(45) Ueda, Y.; Sato, H.; Hirai, C.; Arita, M.; Kimura, A.; Taniguchi, M.; Irisawa, A.; Muro, T.; Saitoh, Y.; Sekiyama, A.; Suga, S. Co 2p-3d Resonant Photoemission Spectroscopy of CoSb3. J. Electron Spectros. Relat. Phenom. 2005, 144-147, 663-666. 
(46) Tanaka, A.; Jo, T. Resonant 3 d , 3 p and 3 s Photoemission in Transition Metal Oxides Predicted at 2 p Threshold. J. Phys. Soc. Japan 1994, 63, 2788-2807.

(47) Winter, B.; Weber, R.; Widdra, W.; Dittmar, M.; Faubel, M.; Hertel, I. V. Full Valence Band Photoemission from Liquid Water Using EUV Synchrotron Radiation. J. Phys. Chem. A 2004, 108, 2625-2632.

(48) Jugnet, Y.; Duc, T. M. Structure Electronique Des Oxydes de Cobalt CoO et Co3O4. J. Phys. Chem. Solids 1979, 40, 29-37.

(49) Alay, J. L.; Hirose, M. The Valence Band Alignment at Ultrathin SiO2/Si Interfaces. J. Appl. Phys. 1997, 81, 1606-1608.

(50) Velasco-Velez, J. J.; Pfeifer, V.; Hävecker, M.; Weatherup, R. S.; Arrigo, R.; Chuang, C. H.; Stotz, E.; Weinberg, G.; Salmeron, M.; Schlögl, R.; Knop-Gericke, A. Photoelectron Spectroscopy at the Graphene-Liquid Interface Reveals the Electronic Structure of an Electrodeposited Cobalt/Graphene Electrocatalyst. Angew. Chem. Int. Ed. 2015, 54, 14554-14558.

(51) Velasco-Vélez, J. J.; Jones, T. E.; Streibel, V.; Hävecker, M.; Chuang, C. H.; Frevel, L.; Plodinec, M.; Centeno, A.; Zurutuza, A.; Wang, R.; Arrigo, R.; Mom, R.; Hofmann, S.; Schlögl, R.; Knop-Gericke, A. Electrochemically Active Ir NPs on Graphene for OER in Acidic Aqueous Electrolyte Investigated by in Situ and ex Situ Spectroscopies. Surf. Sci. 2019, 681, 1-8.

(52) Bernal, M.; Bagger, A.; Scholten, F.; Sinev, I.; Bergmann, A.; Ahmadi, M.; Rossmeisl, J.; Cuenya, B. R. CO2 Electroreduction on Copper-Cobalt Nanoparticles: Size and Composition Effect. Nano Energy 2018, 53, 27-36. 
(53) Sawhney, K. J. S.; Senf, F.; Gudat, W. PGM Beamline with Constant Energy Resolution Mode for U49-2 Undulator at BESSY-II. Nucl. Instrum. Methods Phys. Res., Sect. A 2001, 467468, 466-469.

(54) Seidel, R.; Pohl, M. N.; Ali, H.; Winter, B.; Aziz, E. F. Advances in Liquid Phase Soft-xRay Photoemission Spectroscopy: A New Experimental Setup at BESSY II. Rev. Sci. Instrum. 2017, 88, 1-8.

(55) Verdaguer, A.; Weis, C.; Oncins, G.; Ketteler, G.; Bluhm, H.; Salmero, M. Growth and Structure of Water on SiO2 Films on Si Investigated by Kelvin Probe Microscopy and in Situ XRay Spectroscopies. Langmuir 2007, 23, 9699-9703.

(56) Soldatov, M. A.; Lange, K. M.; Gotz, M. D.; Engel, N.; Golnak, R.; Kothe, A.; Aziz, E. F. On the Origin of Dips in Total Fluorescence Yield X-Ray Absorption Spectra: Partial and Inverse Partial Fluorescence Yield at the L-Edge of Cobalt Aqueous Solution. Chem. Phys. Lett. 2012, 546, $164-167$.

(57) Herranz, T.; Deng, X.; Cabot, A.; Guo, J.; Salmeron, M. Influence of the Cobalt Particle Size in the CO Hydrogenation Reaction Studied by in Situ X-Ray Absorption Spectroscopy. J. Phys. Chem. B. 2009, 113, 10721-10727.

(58) Ketteler, G.; Yamamoto, S.; Bluhm, H.; Andersson, K.; Starr, D. E.; Ogletree, D. F.; Ogasawara, H.; Nilsson, A.; Salmeron, M. The Nature of Water Nucleation Sites on TiO2(110) Surfaces Revealed by Ambient Pressure X-Ray Photoelectron Spectroscopy. J. Phys. Chem. C 2007, 111, 8278-8282. 


\section{TABLE OF CONTENTS}

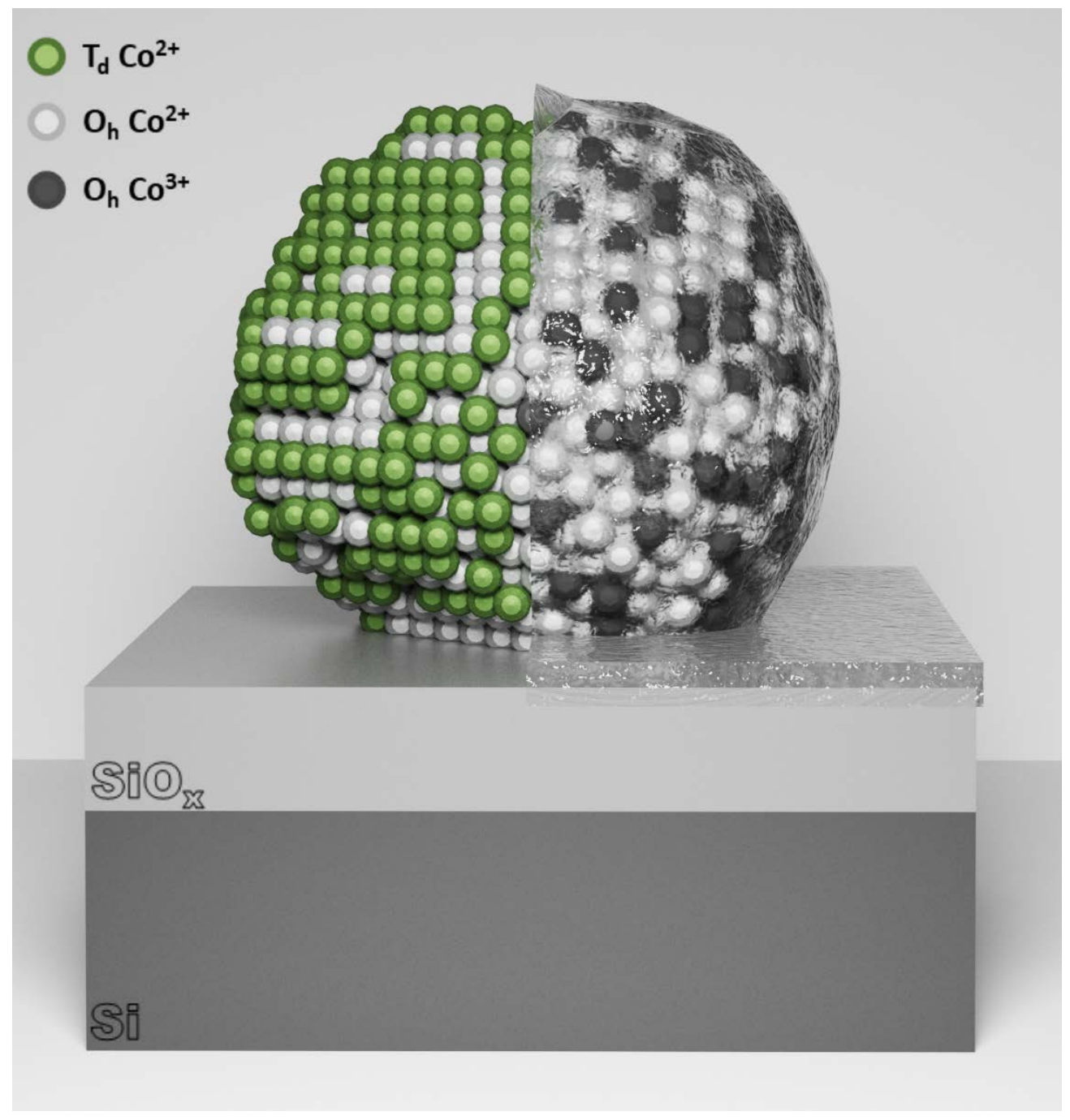

Schematic comparison of one $\mathrm{CoO}_{\mathrm{x}} \mathrm{NP}$ on $\mathrm{SiO}_{\mathrm{x}} / \mathrm{Si}(111)$ substrate without (left) and with adsorbed $\mathrm{H}_{2} \mathrm{O}$ (right). 